Arq. Bras. Med. Vet. Zootec., v.60, n.2, p.356-358, 2008

\title{
Espessura corneana mensurada pelo paquímetro ultra-sônico e pelo microscópio especular Topcon SP-2000P em gatos
}

[Corneal thickness measured by ultrasound pachymeter and by Topcon SP-2000P specular microscope Topcon SP-2000P in cats]

\section{J.J.T. Ranzani, L.A.L. Mobricci*, C.V.S. Brandão, J.L.V. Chiurciu, D.N. Cremonini, G.N. Rodrigues}

Faculdade de Medicina Veterinária e Zootecnia - UNESP

Botucatu, SP

\section{RESUMO}

Avaliou-se a espessura corneana central de 13 gatos normais com microscópio especular de não-contato Topcon SP-2000P e paquímetro ultra-sônico. Foi observado aumento da espessura corneana mensurada pelo paquímetro ultra-sônico comparado ao microscópio especular.

Palavras-chave: gato, espessura corneana, paquimetria, especular

\begin{abstract}
The central corneal thickness of 13 normal cats was evaluated by a Topcon SP-2000P noncontact specular microscope and by an ultrasonic pachymetry was evaluated. An increase on the corneal thickness measured by ultrasonic pachymetry as compared to the specular microscope was observed.
\end{abstract}

Keywords: cat, corneal thickness, pachymetry, specular

\section{INTRODUÇÃO}

A fisiologia das células endoteliais da córnea dos felinos tem características similares às dos humanos, sendo usada comumente como um modelo para estudos endoteliais. A mensuração da espessura corneana é um meio para monitorar a função e a integridade das células endoteliais (Gilger et al., 1993) e é útil para acompanhamento e diagnóstico de estados patológicos que envolvem a córnea (Yamane, 1996; Modis et al., 2001). A lâmpada de fenda óptica, o ultra-som e a paquimetria com microscopia especular são métodos amplamente usados e aceitos para mensurar espessura corneana (Modis et al., 2001). Existem vários tipos de paquímetros, sendo o paquímetro ultrasônico e o eletromecânico os mais utilizados.

A paquimetria ultra-sônica é um método, in vivo, preciso, disponível para mensurar a espessura corneana. Não toca diretamente a córnea, mas faz contato por meio de um menisco de água deionizada, portanto, nenhuma alteração é induzida na córnea pela probe durante a mensuração. O tempo requerido para a energia ultra-sônica atravessar a córnea é registrado e a espessura é calculada pelo uso de uma constante de velocidade do som através da córnea, de $1,630 \mathrm{~m} / \mathrm{s}$ no cão (Gilger et al., 1991) e 1,590m/s no gato (Gilger et al., 1993). Quando a sonda toca a córnea, o aparelho é acionado, e a partir de então, cada medida deve ser considerada em função do desvio-padrão a ela relacionado, o qual indica a adequada posição da sonda em relação à superfície corneana (Yamane, 1996).

A paquimetria eletromecânica obtida pelos microscópios especulares é realizada por meio do contato ou não com a superfície da córnea, sendo tal avaliação apenas possível em relação a pontos localizados na porção central dessa estrutura.

Recebido em 9 de março de 2007

Aceito em 30 de janeiro de 2008

* Endereço para correspondência (corresponding address)

R. Arthur Carlos Ferreira, 63 - 12244-451 - São José dos Campos, SP.

E-mail: lumobricci@yahoo.com.br 
O microscópio especular de não-contato Topcon SP-2000P é capaz de realizar microscopia especular e paquimetria ao mesmo tempo, fornecendo informações do status corneano, tal como morfologia e densidade das células endoteliais. Focando no endotélio, esse equipamento fornece imagens especulares e mensura a distância focada, que pode ser calculada como espessura corneana. No caso de córneas semitransparentes ou opacas, a imagem capturada é difícil ou impossível de ser obtida, representando as limitações desse aparelho (Modis et al., 2001).

A proposta deste estudo foi comparar as medidas centrais da espessura corneana encontradas no paquímetro ultra-sônico e no microscópio especular em olhos normais de gatos.

\section{MATERIAL E MÉTODOS}

Utilizaram-se 13 gatos domésticos, sem raça definida, machos e fêmeas, sem patologias oculares, anestesiados com tiletamina e zolazepan $(8 \mathrm{mg} / \mathrm{kg}$ - IM) para realização dos exames.

Inicialmente foi realizada a paquimetria eletromecânica utilizando microscópio especular de não-contato Topcon SP-2000P. Para tal, os animais foram posicionados a uma distância de $25 \mathrm{~mm}$ do aparelho, e analisadas áreas fotográficas de 0,2 a $0,5 \mathrm{~mm}$. Posteriormente, a paquimetria ultra-sônica foi executada por um paquímetro Nidek UP-1000, após instilação tópica de colírio anestésico. A espessura corneana foi mensurada por meio de uma probe ultra-sônica, de $20 \mathrm{mHz}$, com velocidade ultrasônica de 1,590m/s. A espessura corneana foi mensurada no centro da córnea por meio de cinco medidas em cada olho. O aparelho calculou, automaticamente, o desvio-padrão referente às leituras obtidas.

\section{RESULTADOS E DISCUSSÃO}

A média da espessura corneana foi de 507 e $519 \mu \mathrm{m}$, em ambos os olhos, mensuradas nos paquímetros especular e ultra-sônico, respectivamente. Os valores encontrados foram mais baixos que os encontrados por outros autores, que citaram valores de paquimetria ultra-sônica entre 569 e $592 \mu \mathrm{m}$ (Chan-Ling et al.,
1985; Ling, 1987) e microscopia especular de $560 \mu \mathrm{m}$ (Peiffer et al., 1981). Não foi observada diferença significativa entre os olhos direito e esquerdo. Não houve diferença de espessura corneana entre machos e fêmeas, e não foi realizada comparação entre as idades dos animais.

Foi observado aumento da espessura corneana mensurada pelo paquímetro ultra-sônico quando comparado ao microscópio especular (Tab. 1), semelhante ao resultado encontrado em gatos por Gilger et al. (1993). Outros autores observam resultados semelhantes em seres humanos (Bovelle et al., 1999; Modis et al., 2001).

Tabela 1. Valores obtidos da espessura corneana por meio de paquimetria ultra-sônica e especular em gatos

\begin{tabular}{ccc}
\hline & $\begin{array}{c}\text { Paquimetria } \\
\text { (US) }\end{array}$ & $\begin{array}{c}\text { Paquimetria } \\
\text { (Especular) }\end{array}$ \\
\hline Olho direito & $515 \pm 73 \mu \mathrm{m}$ & $510 \pm 85 \mu \mathrm{m}$ \\
Olho esquerdo & $523 \pm 68 \mu \mathrm{m}$ & $504 \pm 83 \mu \mathrm{m}$ \\
\hline
\end{tabular}

Várias teorias têm sido formuladas a respeito dessa diferença de espessura encontrada nos aparelhos. De acordo com Gilger et al. (1993), o uso de o microscópio especular para mensurar a espessura corneana em animais requer anestesia geral. Com o uso de anestesia dissociativa, as pálpebras permanecem abertas durante a anestesia, o que resulta em desidratação e afinação da córnea pela evaporação de filme prélacrimal. Isso potencialmente interrompe a mensuração da espessura corneana, e essa alteração pode resultar em mensurações mais finas. Além disso, por determinar a espessura a partir das superfícies posteriores do filme lacrimal e da membrana de Descemet, o microscópio especular pode resultar em erros de medições de até 30 $\mu \mathrm{m}$ (Yamane, 1996).

\section{CONCLUSÃO}

Ambos os aparelhos são capazes de realizar mensurações de paquimetria, mas, como observado em seres humanos, não podem ser usados indiscriminadamente, sem o conhecimento prévio de que a espessura corneana, obtida pela paquimetria eletromecânica utilizando o microscópio especular de não-contato, será menor que a obtida com o paquímetro ultra-sônico. 


\section{REFERÊNCIAS BIBLIOGRÁFICAS}

BOVELLE, R.; KAUFMAN, S.C.; THOMPSON, H.W. et al. Corneal thickness measurements with the Topcon SP-2000P specular microscope and an ultrasound pachymeter. Arch. Ophthalmol., v.117, p.868870, 1999.

CHAN-LING, T.; EFRON, N.; HOLDEN, B.A. Diurnal variation of cornel thickness in the cat. Invest. Ophthalmol. Visual Sci., v.26, p.102-105, 1985.

GILGER, B.C.; WHITLEY, R.D.; McLAUGHLIN, S.A. et al. Canine corneal thickness measured by ultrasonic pachymetry. Am. J. Vet. Res., v.52, p.1570-1572, 1991.

GILGER, B.C.; WRIGHT, J.C.; WHITLEY, R.D. et al. Corneal thickness measured by ultrasonic pachymetry in cats. Am. J. Vet. Res., v.54, p.228-230, 1993.

LING, T. Osmotically induced central and peripherical corneal swelling in the cat. Am. J. Optomol. Physiol. Optics, v.64, p.674-677, 1987.

MODIS, L.; LANGENBUCHER, A.; SEITZ, B. Corneal thickness measurements with contact and noncontact Specular Microscopic and Ultrasonic Pachymetry. Am. J. Opthalmol., v.132, p.517-521, 2001.

PEIFFER, R.L.; DEVANZO, R.J.; CONHEN, K.L. Specular microscopic observations of clinically normal feline corneal endothelium. Am. J. Vet. Res., v.42, p.854-855, 1981.

YAMANE, R. Ceratoscopia, ceratometria, topografia e paquimetria corneana. In: DOMINGUES, D.A.; PENA, A.S.; NETO, P.G. (Eds). Semiologia ocular, Rio de Janeiro: Cultura Médica, 1996. p.116-136. 